\title{
Smart technology in planning cities that suffer the effects of displacement in war countries
}

\author{
Youssef Saied*, and Inna Rodionovskaya \\ Moscow State University of Civil Engineering, Yaroslavskoe shosse, 26, Moscow, 129337, Russia
}

\begin{abstract}
The aim of this paper is to identify the role that smart city technology can play in the development of cities in countries that have been affected by war, for example the Syrian Arab Republic and specifically cities that have been subjected to the multiplication of forced displacement movements, imposes significant burdens on all societies, but provides opportunities for development in adopting a rights-based approach that meets the needs of displaced people and host communities. In addressing the effects of displacement within development plans, access to education, Live and reduce the damage to the environment and build social cohesion, smart city solution can transform these challenges to an opportunity make a technological change aims to improve services in an orderly, influential, and provide applications these cities to achieve an impressive leap and able to analyse a large amount of data, Thus making plans for the future and using these data to make effective changes and transform them into intelligent systems that understand the needs, lifestyles, behaviour and culture of the population. Of course, the shift to smart technology requires the participation of local communities as well as all planning entities in order to achieve the best possible rate of success.
\end{abstract}

\section{Introduction}

Many people now live in cities and the urban population of the world is expected to rise by $54 \%$ in 2014 to $70 \%$ by 2050 , Cities are the main drivers of economic growth and account for $80 \%$ of world GDP, but also consume around $75 \%$ of the world's primary energy, responsible for $70 \%$ of global greenhouse gas emissions (GH6) in urban-related sectors (transport, construction and maintenance, Management and energy ...) raising issues of sustainability [1].

Rapid and unplanned urbanization led to the growth of slums, housing, lack of infrastructure, social segregation, exclusion, and also caused congestion, air pollution and noise, which greatly threatened culture and heritage Urbanization trends dictate the need for strategic and innovative approaches to urban design, planning, management and governance. The accompanying trends in ICT increasingly include business functions, city logistics, networks, transport and delivery, basic services, environmental management systems, government processes and data-based industries such as finance and interactions, Rapid urbanization creates an urgent need to find smarter ways to manage challenges such

\footnotetext{
Corresponding author: youssef.h.saied@gmail.com
} 
as traffic congestion, air pollution, high crime rates and the difficulty of waste management, the main objective of the Smart City as a concept is to manage and organize the entire city through technology, which will improve services for the government and citizens alike. The Smart City is able to solve many of the city's challenges to improve the quality of life through intelligent technology such as smart economic growth and management Smart government and smart services to citizens, However, the idea of a smart city is still new and growing, which makes its concept very broad. For this reason, smart city examples can vary greatly in size, type, and each example has its distinctive features along with the historical track of development, the current situation and the future. The use of ICT tools Can help manage and analyse diverse information and data so that they can be used effectively in contingency and disaster planning in advance $[1,2]$.

In the architectural activity, the formation of projects is a kind of projection of the needs and desires of users on this project, so there is a need to know the needs and desires of the population and take into account their characteristics and their general characteristics in terms of cultural and social, so the designer must feel a kind of prediction of these requirements, In this case, great assistance in the formation of urban space using the future design technique, which is used to develop the elements of architecture in an advanced, influential and objective, this design reflected through the tangible results for users and therefore the architect is a programmer Smart architectures are used to accurately predict the needs of users and create an environment suitable for these needs [3, 4] in the formation of diverse and new architectures of architectural spaces. This provides resources and utilizes sustainable renewable energies. This requires a deep reinterpretation of the city and its areas as well as planning and how to manage them. It is recommended to activate the use of predictive configuration of the future of the Smart City through a specific intelligent technique of design as a method, method and intelligent concept to predict the threads according to the appropriate standard parameters $[5,6,7]$.

\section{Background}

Although there is some sort of consensus that the main factor of the smart city is the ability to manage the city for its services and infrastructure, there is a wide range of smart city definitions and a common definition has not yet been defined yet two distinct trends can be clearly identified with regard to the main aspects that must be Take the smart city into account [2]. On the first hand, there is a wide range of concepts that focus on only one aspect of urban (technological, ecological, etc.) where it ignores the rest of the factors involved in the development of the city. This set of unidirectional definitions is a misunderstanding that the ultimate goal of the Smart City is in a new approach to urban will including dealing with all aspects and achieving coherence that occurs in the real life of the city, as improving one part of the urban ecosystem does not mean that all problems have been addressed, On the other hand, there are some writers who emphasize the quality and direction of the fundamental difference in the concept of smart city is the interconnection and communication between all urban intertwined and interconnected aspects between urbanization, infrastructure, social and institutions at the same time reflected this intervention in the concept of smart city, The infrastructure is a central part of the smart city and the technological element is the technical element that makes it possible in addition to integrating all systems that become essential for a smart city later on .

It is surprising that there is no definition of a specific framework in general to define the concept of a smart city, where many people believe that it is related to technology and to some extent this is true as technology is a key enabling element and is of great importance as it plays an important role in the operation and management of cities such as transport Intelligent, energy, smart buildings etc., But it is much broader than that. It is about 
understanding that the elements of empowerment in the Smart City transcend the digital frontier only. The establishment of an ecosystem in which the population, investors, companies and government are all interlinked and contribute to a shared and integrated vision to create a more productive and appropriate city for the population, Possible quality of services.

The UK-based Canter for Cities2 has sought to clarify several points about the Smart City concept through several broad categories that rely on a broad, diverse database that focuses on the local community and population. Where the role of cities and urban communities is focused on innovation, creating new ICT-based solutions and broad and comprehensive infrastructure deployment [8], In addition to the promotion and activation of applications based on information technology and communication, where quality of life and quality of services provided to the citizen a major priority and the next step is the diverse role of smart cities [9]. FP7-ICT and CIP ICT-PSP developers and programmers stimulate and encourage the testing of smart cities as an open-source innovation experience based on users' needs. The implicit goal of these initiatives is to make cities and urban areas as well as rural and regional environments changeable environments and environments that achieve appropriate innovation and development Needs and desires of the population at the same time [10].

At the moment, there are many concepts that explain the concept of the Smart City, which is increasing and continues to expand. Many researchers focus mainly on modern technology, communication and technical information. At the same time, definitions are not limited to these trends, but actually extend to other areas. On this theory Caragello and others 2011, [11] Who pointed out that the city is smart when it invests in human capital, social capital and various services such as transport, ICT, waste treatment and power generation. It must also achieve economically and socially sustainable growth, provide a very good quality of life and good management of natural resources through participatory governance. Crawford discussed 2014[12] The importance of community participation and the quality of management, management and leadership to ensure the proper implementation of the concept of the city smart and achieve the best possible quality ratio in addition there is also a need to create an interactive environment between the community and modern technologies to enable the community to optimize the use of these technologies [13]. There are several attempts to visualize the smart city concept, one of which is through the development of methods of comparison, indicators and statistics to evaluate and measure the effects. The purpose of these standard comparisons is to compare smart cities based on different factors, influences and ideas, the performance measurement method is used to evaluate smart cities from different perspectives such as sustainability factor, city high resilience performance, local trial, efficiency, urban competitiveness and new urban will [14].

\section{Discussion}

In the Arab countries there are two common transformations to create smart and sustainable cities, the Greenfield model and the Brownfield model, only 3 Countries with successful strategic plans and regulatory framework on use of ICT technology for transition to smart and sustainable development in various spheres. In the recent years the instable situation, several conflicts and political developments effected the economic performance and development. Syrian Arab Republic haven't embraced the concept of smart cities, the current situation and because a several common challenges with other Arab Countries include:

a) Inadequate sustainable financial investment in smart city projects

b) Political instability and high rate of youth unemployment.

c) Inadequate ICT infrastructure; technological obsolescence. 
d) Difficulty in citizen adjustment to new ways of accessing services [15].

The majority of Lattakia is still stable in terms of security, but the hosting of a large number of displaced people has led to increased competition for services and assistance and livelihood opportunities. Although the province still records the lowest prices of food in the country has been identified 330,000 people in need of food aid in areas covered by MSNA in Lattakia, due to its relative stability and availability of services, stable areas in the centre and south of the governorate have seen a large influx of displaced persons. Most estimates put the number of IDPs between 580000 and 760000, with the number of IDPs in the Syrian Arab Republic at 7,600,000, According to the MSNA, there are 450,000 IDPs in rented housing, 220000 living with host families and 23,000 in camps, surpassing the total population of the city 1.2 million Which means that the number of displaced people is bigger than the number of local residents in the city of Lattakia $[16,17]$.

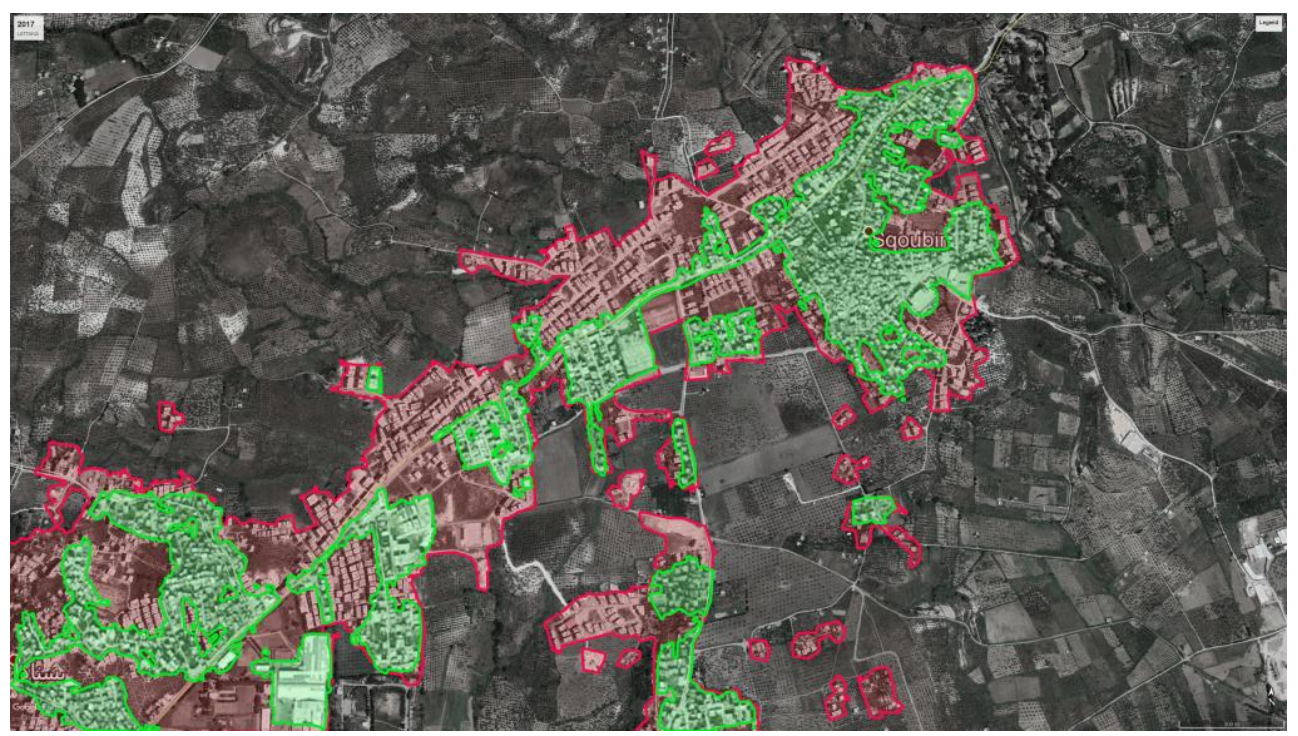

Fig. 1. Population growth in the village of Sakubin, Lattakia between 2004 and 2017.

Impact of Refugees, Internally Displaced Persons and Other Displaced Persons on Development:

The relationship between development and displacement is a two-way relationship. Development has an impact on population movements and displacement. Implications for development are reflected on families, communities and nations, Stagnation in development presents pressures such as poverty, poor governance and political instability that increase vulnerability to humanitarian crises and drive them to leave in search of safety. As populations migrate, host communities may face changes that can hinder economic, social and human development, despite these constraints, can the gap between displacement and development plans be helped to benefit IDPs and host communities.

Dealing with displacement issues in the framework of development plans The involvement of ministries concerned with development, finance, urban planning, employment, education, health and environmental care, as well as ministries dealing with policies and programs for refugees and internally displaced persons, should be involved. Civil society should also be involved, especially humanitarian organizations providing assistance to this group of persons and representatives of Municipalities and others familiar with the impact of displacement on local development. 


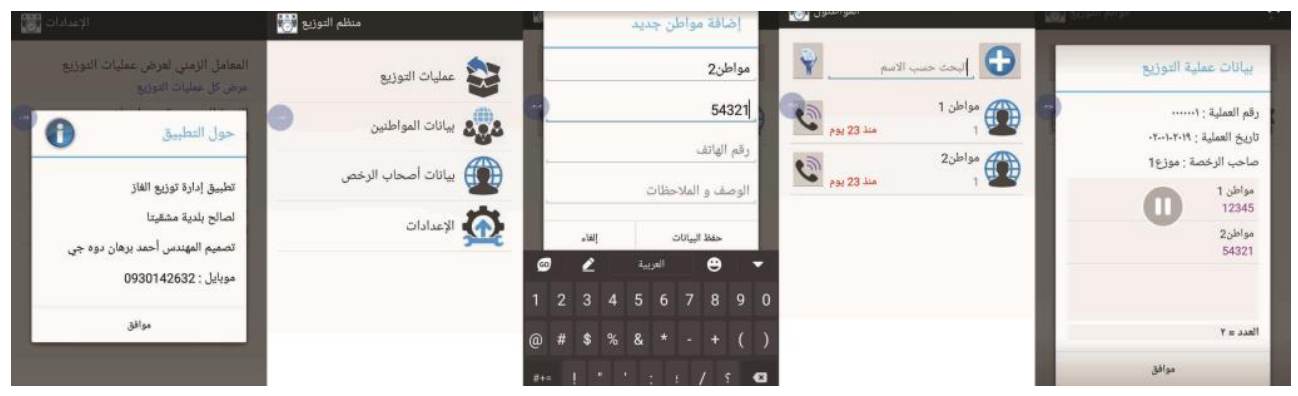

Fig. 2. The first application to regulate the distribution of fuel in the city of Lattakia.

As a result of the need to use technology and its need to improve the provision of services to citizens and the collection of a comprehensive database to help analyse the needs and requirements of the population and to anticipate any service crisis and work to address them before the aggravation and the result of the knowledge of the new generation of the population (young people) on the modern technology in the world, a group of developers launched the first service application that regulates the distribution of fuel to the population by collecting a database for all the population in the target area electronically and organizing the distribution process and facilitate to avoid the exacerbation of the fuel crisis in Lattakia, See this mechanism to cover all the needs of the service population later, it mentions that this application has been programmed to individual initiative without government supervision, which leads us to question the role of the government and push it to adopt small projects to support, develop and provide facilities in order to achieve better quality services to the population.

\section{Recommendations}

Observations and recommendations on development in vital sectors The best way to achieve these benefits is synergy between national Governments, local administrations, the international community, civil society and migrants in development and vital sectors

\subsection{Health}

Strengthening the capacity of existing health facilities (clinics, hospitals and staff ...) and improvements that will positively impact community development in the aftermath of more sustainable solutions [16].

Provide internally displaced persons with specialized local services to meet their mental and psychological health needs when IDPs are unable to access these services in host communities.

Involve displaced people in the provision of health services to strengthen health systems.

\subsection{Education}

Strengthening Existing Infrastructure (Buildings Teachers Schools ........) [16].

Provide sustainable alternatives to improve the level of educational attainment.

Engaging displaced people in strengthening educational systems in countries to ease the burden on the educational system as a result of displacement. 


\subsection{Labor markets, human capital and financial shifts}

Adopting the necessary legislation and implementing it.

To benefit from the expertise and capabilities of displaced persons to advance the development of vital sectors and to fill the gap in basic services [16].

Encourage commercial banks and insurance companies to provide services for business development.

Conduct quantitative and qualitative research on the impact of the situation of IDPs on the economy of host communities to assist the state and other actors in developing strategies for livelihoods in emergency and chronic crises.

\subsection{Environmental Sustainability}

Integrating environmental sustainability considerations into local and administrative development plans from the earliest stages with a view to reducing damage to the environment at later stages [16].

Providing financial and technical support to the population for water conservation, application of sustainable agriculture techniques and access to renewable energy resources in order to avoid the causes of tension due to lack of resources and to enhance the ability to achieve development goals and move towards a smart city.

Educating the local community and the displaced about the impact of environmental degradation on everyone.

\subsection{Cohesion and social stability}

Providing international assistance in order to alleviate the burdens of the host communities so that they can achieve development and achieve the successive steps to reach a smart city. To implement policies based on the principle of non-discrimination in order to achieve social inclusion and to eliminate the causes of discord between societies.

Encourage decentralization of emergency and extended emergency response procedures to build local capacity.

\subsection{In addition to taking into consideration}

Public spaces and high quality planning streets help to support the local economy, communication, culture and creativity.

Addressing the threat of rapid urbanization through good design with the appropriate density, achieving sustainable economies of scale and promoting sustainable urbanization.

Mixed urban uses and limited specialization in land use. Mixed land use planning helps to create local jobs, boost the local economy, reduce dependence on cars, encourage pedestrians, bicycles and other non-motorized transport, preserve landscapes, mitigate greenhouse gas emissions, strengthen public services and support mixed communities and. Local economies [15].

Energy efficiency and resources This requires growth management that addresses consumption and resources through strategic planning, policies and measures that focus on buildings, appliances, transportation, agro-industries and services using resources in a sustainable manner.

When preparing agendas for urban areas is to ensure that investment in ICT is not neglected.

Preservation of cultural origin must be planning and design by smart city approach in line with local culture through public participation. [1] 
The balance between general needs and economic considerations to respond to the needs of citizens who are more able to mobilize and demand work using information and communication technology and create a competitive environment between cities.

\section{Challenges}

There are different types of smart technology that can be used effectively in the post-war period, especially in communications. Generally, countries that have suffered wars seek international assistance:

- There is no previous experience with the planners and the priority-setting in the application and the teams that will collect the data in the first stage and thus rely on the individual studies and researches. Various cases of different treatment and analysis of the data are expected due to poor coordination in the first stage due to poor research Transforming cities suffering from the effects of wars and conflicts at the local level in the Syrian Arab Republic.

- Some countries prohibit the use of high-tech information and communications technologies without government approval.

- The weakness of the infrastructure of the services necessary to start the process of transformation into a smart city, especially in the field of telecommunications. In the case of the Syrian Arab Republic, the electricity sector may be a major obstacle because of the severe damage caused by the war in all sectors of generation, transmission, conversion and consumption, the fuel needed to operate the electrical system [18].

- The international sanctions imposed on the Syrian Arab Republic, which caused a great handicap in the field of supplying modern technologies or developing them within the Syrian Arab Republic in addition to the difficulty of supplying the raw materials, fuel and equipment necessary to begin the process of development and the poor economic situation that hinder the return of many displaced people to their oginal areas, Their participation in the development of priorities and needs in the first phase.

- The security and stability situation where part of the Syrian Arab Republic is still outside the control of the Syrian state and is suffering from chaos in light of the big international intervention that exploits the resources in those areas wrongly [16].

- The lack of sufficient funds to finance research plans and studies in the field of smart cities and their gradual application to the population in addition to the lack of legislation and laws necessary to develop key principles on the map of the transformation towards smart cities.

In addition to the other group of challenges from the organizational and social aspects and the acceptance of the population to shift to the use of modern technologies and rely on them in providing services and basic needs in addition to the large numbers of displaced persons and the absence of security and stability in several areas and the sense of unfairness and equality and lack of availability of services and the difficulty in securing the basic resources to start projects And the complex political situation of the country in a post-war situation. Thus, the state of development and reliance on modern technologies in the post-war period is very complex and intertwined, The number of conflicts in the Arab world in recent years has made the Arab region face many economic, social and political challenges such as poverty, insecurity, inequality, lack of basic needs of the population such as electricity, water and energy, Insufficient communication infrastructure, lack of information, very low utilization of information and communications technology, high cost of using ICT for Smart City and sustainable development [18]. 
As well as the technical problems in the field of information and communications technology, the right to use it, the security and privacy issue, and the weakness of local ICT capabilities. Most statistics indicate that almost all equipment has been imported and therefore decisions to purchase this equipment in case of political and economic instability may not achieve The post-war cities can experience insufficient financial support from governments due to economic downturns and human resources, especially technology workers. Consequently, most of the technological challenges of most projects Organizational, not technical and acceptance of the local community, which plays an important role in accepting these projects and work to develop them [19].

\section{Conclusion}

The Syrian Arab Republic did not adopt the concept of smart city before the war, It is difficult in the present situation to define the concept of the smart city because of the prevailing conditions, Information and communication technology and smart technology can play an important role in improving the quality of services and developing them after the war, Therefore, there is a need to integrate smart information technology into plans and strategies. Where it is possible to integrate the different information technologies in all fields and facilitate to exchange the information quickly and accurately between different scenarios for the development of urban clusters, there are different types Such as large data processing systems in the analysing community requirements and processing these data in a timetables.

The cultural and heritage situation of the city must be taken into account, and the characteristics and nature of the city should not be neglected and the historical situation of the city should not be adversely affected by changing these characteristics and its architectural and urban character. Rather, it should be adapted and developed with sustainable development plans and the smart city, people's acceptance of this transformation is an important factor in the transition to smart city.

\section{References}

1. United Nation Conference on Housing and Sustainable Urban Design HABITAT III ISSUE PAPERS,21 - SMART CITIESm, (2011)

2. T. Nam, T. Pardo, Conceptualizing smart city with dimensions of technology people and institutions. ACM International Conference Proceeding Series, 282, (2011)

3. N. Saprykina, Forecasting technology as a method of modeling and building Smart City concept. IOP Conference Series: Materials Science and Engineering, 365, (2011)

4. Saprykina N A Tezaurus parametricheskoj paradigm formirovanija arhitekturnogo prostranstva // «Architecture and Modern Information Technologies» / Mezhdunarodnyj jelektronnyjsetevoj nauchno-obrazovatel'nyj zhurnal «Arhitektura i sovremennye informacionnyetehnologii» 2017. - 3(40). - s. 281-303

5. Proekt hydro-net jekologicheskaja utopija Available at: http://www.intelligent.lv/ru/ proekthydronet-ekologiceskaja-utopija/83_20041.html

6. HYDRO-NET Available at: http://www.dezeen.com/2008/02/08/hydro-net-byiwamotoscott/

7. Zastrojka pribrezhnoj zony Asana (Juzhnaja Koreja) Available at: http:// strigenov. livejournal.com/62779.html

8. Eurocities: Strategic Policy Paper on Broadband in Cities (2010) 
9. Eurocities: Cities and Innovation in Europe. Discussion paper (2010)

10. E. Von Hippel, Democratizing Innovation. The MIT Press, Cambridge (2005)

11. A. Caragliu, C. Del Bo, and P. Nijkamp, "Smart Cities in Europe," J. Urban Technol, 18, no. 2, pp. 65-82 (2011)

12. S. Goldsmith and S. Crawford, The Responsive City: Engaging Communities Through Data-Smart Governance, 1 edition. San Francisco, CA: Jossey-Bass, (2014)

13. S. Kumar, "Institutional Arrangements for Managing Large-Scale Recovery: Key Lessons from 2004 Tsunami," in Recovery from the Indian Ocean Tsunami, R. Shaw, Ed. Springer Japan, pp. 103-119 (2015)

14. L. Anthopoulos, M. Janssen, and V. Weerakkody, Comparing Smart Cities with Different Modeling Approaches, presented at the International World Wide Web Conference Committee (IW3C2), Florence, Italy, (2015)

15. Wafula M. ICT policies and plans for transition to smart and Sustainable Development in Arab region [Internet]. ITU; (2016). Available from: https://www.itu.int/en/ITUD/RegionalPresence/ArabStates/Documents/Reports/ICT_policies_plans_for_transitio n_to_SS_Development_in_Arab_Region.pdf

16. report :Regional Analysis in Syria .Characterization of Governorates p44-p46, (2014)

17. Report: International Migration Report Migration, Displacement and Development in a Changing Arab Region, (2015)

18. A. Belal, E. Shcherbina, Smart-technology in city planning of post-war cities, $\mathbf{3 6 5}$ (2018)

19. S. Alawadhi, A. Aldama-Nalda, H. Chourabi, J. Gil-Garciam, S. Leung, S. Mellouli, T. Nam, T. Pardo, H. Scholl, S. Walker, Building Understanding of Smart City Initiatives. Lecture Notes in Computer Science, pp.40-53 (2012) 